\title{
Competency-Based Modules in Food Sanitation and Safety
}

\author{
Abigail llagan-Manzano \\ College of International Tourism and Hospitality Management, Lyceum of the Philippines \\ University, Batangas City, 4200 Philippines \\ jakelaguador@yahoo.com, Fax: +63 43 723-0595
}

DOI: $\quad 10.6007 /$ IJARBSS/v3-i8/125 URL: http://dx.doi.org/10.6007/IJARBSS/v3-i8/125

\begin{abstract}
The study was conducted to assess the food safety practices among food service establishments in order to increase awareness among students the dangers of food poisoning. The output of this study may serve as a tool for information dissemination. The study used the descriptive method research. The respondents of the study were the supervisors of selected fast-food chains and deluxe hotels in Manila. Descriptive Statistics was used to describe the basic features of the data in the study and to validate the data gathered. The safety of consumers is the paramount responsibility of any food service establishment. Standards, procedures and guidelines are developed to prevent the outbreak of food borne illnesses and intoxication. However, these standards, procedures and guidelines as food sanitation and safety will be meaningless if they are not study implemented through education, information, dissemination, and training among the personnel. Food safety is everybody's concern. It is in this context that the researcher tried in her own lifestyle way to help by proposing these competency-based modules.
\end{abstract}

Keywords: food safety, sanitation, competency-based module, food industry, hospitality management

\section{Introduction}

The hospitality industry is the world's largest industry generating five hundred billion U.S dollars and employing hundreds of million people worldwide. This vast system consisting of several sectors covers government and non-government organizations as well as educational institutions.

In accordance with the provisions of the Republic Act No. 7722 known as the Higher Education Act of 1994, it is apt to rationalize the undergraduate tourism, hotel and restaurant, hospitality management education in the country to keep a pace with the demands of global competitiveness. This rationale resulted to the ramification of the Philippine Tourism education system to produce graduates who will not only survive but also thrive in a borderless economy. A shift from supply-driven to market driven curriculum in terms of content and structure was 
adopted in order to be more responsive to the needs of the industry. New programs emphasize skills and competencies instead of just managerial theory. The course incorporates subjects on sustainable development and international standards and practices to address issues that arise from market imperfections and the challenges of globalization. In effect, the curriculum becomes flexible and creative on the part of Higher education institutions.

From the issued Memorandum Order No. 30 by the Commission on Higher Education(CHED) series 2006, degree programs must be designed to equip students with competencies related to the basic and core requirements that are associated with major and minor areas of concentration and elective courses.

One of the competencies that was highlighted in tourism education is sanitation and safety course. According to Walker (2004) additional management skills like supervisory training, sense of urgency, accounting, sanitation and safety are also essential as the level of the professionalism rises in the twenty-first century. As per CHED requirement, it implies that a hospitality future practitioner and students should have introduction on the value of safety, sanitation and hygiene principles and sound practices to prevent outbreak of food borne illnesses and intoxication.

Food safety is becoming a vital requirement of the hospitality industry. As the dollar amount spent by consumers on food away from home has increased, so too has the extent to which food products from the industry impact the health and well being of the nation. Many factors are shaping the industry's future: international and multinational; influences, globalization, increasing expectations, as well as, changing patterns of leisure.

Many factors attributed to make food unsafe are: sources of raw materials, process, storing, handling and the people involved in the process are vital consideration in safety. The kind of sanitary precautions associated with food service systems that prepare food, and then transport it elsewhere are not universal since the food are handled by more people with different techniques. It is clear that most of the operators responded with the highest standards of sanitation. This is not surprising considering a common knowledge on a single incident of food poisoning, broadcasted to the world via media, can mean the end of the business.

As such, it is a challenge to change the mentality and attitude of people to be positive about hygiene practices and training. It is not the certificate that matters what is more important is getting this message across to rank and file staff. However, management has to be at the forefront of hygiene practices in order for it to filter down to their team.

Most people would agree that food hygiene training is necessary to enable staff to fulfil their potential, to effectively carry out their duties and responsibilities, and to improve their skills. But the training has to be of high standard as effective training increases job satisfaction, improves performance, and reduces the amount of instruction and supervision required. But most importantly, it ensures the safety of the food served to customers. 
The school authorities posses moral responsibility to the future of the country. Safety education is one of tremendous importance in the peoples private and public life. Colleges and Universities may improve and make functional their courses by the inclusion of practices and activities geared toward an adequate development of safety concept.

In this line of thought, this study was conducted to assess the food safety practices among food service establishments in order to increase awareness among students the dangers of food poisoning. The output of this study may serve as a tool for information dissemination.

\section{Objectives of the Study}

The study was conducted to develop a set of proposed competency based modules in food sanitation and safety. It aimed to determine the food sanitation and safety standards as recommended by the Sanitation Code of the Philippines; Good Manufacturing Practices (GMP); Standard Sanitary Operating Process (SSOPs); Hazard Analysis and Critical Control Points (HACCP); Serv Safe; ASEAN Common Competency Standards for Tourism Professionals; and Food Safety Management System (ISO 2200). It is also intended to determine the areas of competencies are needed to be harmonized for commercial kitchen staff/steward; the extent of practice of the harmonized standards in food sanitation and safety in hotels and fast-food chain; and there significant difference on the extent of practice the ratings of the participating hotels and fast-food chain.

\section{MATERIALS AND METHODS Research Design}

The qualitative research method was used in this research study particularly the descriptive type of research investigation. The purpose of this type of research is to describe objectively the nature of the situation under study.

\section{Participants}

The participants of the study included the kitchen supervisors of the five (5) deluxe hotels and five (5) fast-food chains in Metro Manila. The random sampling method was applied in the selection of deluxe hotel and fastfood chains participants for the study. This is a method of sampling that allows the population to have an equal chance of being selected. For purpose of confidentiality, the participating deluxe hotels and fast-food chains will be coded as hotel $A, B, C, D$ and $E$ and for fast-food chains, fast-food 1,2,3,4,and 5. There were twenty-eight (28) respondents from the ten (10) participating establishments. Table 1 shows the breakdown of respondents per establishments. 
Table 1.

Profile of the Respondents

\begin{tabular}{|c|c|c|c|c|}
\hline \multirow{5}{*}{\begin{tabular}{ll}
\multicolumn{2}{c}{ Participants } \\
1. Gender \\
Male \\
Female & \\
& Total
\end{tabular}} & \multicolumn{2}{|c|}{ Hotel } & \multicolumn{2}{|c|}{ Fast Food Chain } \\
\hline & $f$ & $\%$ & $f$ & $\%$ \\
\hline & 7 & 58 & 14 & 87.5 \\
\hline & 5 & 42 & 2 & 12.5 \\
\hline & 12 & 100 & 16 & 100 \\
\hline \multirow{7}{*}{$\begin{array}{l}\text { 2. Educational } \\
\text { Attainment } \\
\text { Technical Course } \\
\text { BSHM } \\
\text { BSND } \\
\text { BSFT } \\
\text { College undergraduate } \\
\text { Total }\end{array}$} & $f$ & $\%$ & $f$ & $\%$ \\
\hline & 3 & 25 & 0 & 0 \\
\hline & 6 & 50 & 4 & 25 \\
\hline & 0 & 0 & 1 & 6 \\
\hline & 0 & 0 & 1 & 6 \\
\hline & 3 & 25 & 10 & 63 \\
\hline & 12 & 100 & 16 & 100 \\
\hline \multirow{5}{*}{$\begin{array}{l}\text { 3. Length of Service } \\
\text { less than } 5 \text { years } \\
\text { 5-10 years } \\
\text { 11-15 years } \\
\end{array}$} & $f$ & $\%$ & $f$ & $\%$ \\
\hline & 6 & 50 & 12 & 75 \\
\hline & 5 & 42 & 4 & 25 \\
\hline & 1 & 8 & 0 & 0 \\
\hline & 12 & 100 & 16 & 100 \\
\hline
\end{tabular}

In Table 1 presents the profile of the respondents from participating hotels and quick restaurants / fast-food chains. Males outnumber the females in both types of establishment. Kitchen personnel in hotels were mostly holders of baccalaureate degree in hospitality management (50\%). Equal number of kitchen personnel was either college undergraduate or graduates of technical courses. In terms of length of service majority of the respondents both in hotels have been in the industry for less than 5 years. Only 1 has been in the industry for 1115 years while the remaining respondents have been there for 5-10 years.

The same pattern was seen for those in fast food chains. The only difference was that $63 \%$ of the kitchen crew were college undergraduate while $37 \%$ were graduates of BSHM (25\%), BSND(6\%) and BSFT(6\%), nobody among the respondents finished technical course.

\section{Instrument}

A researcher designed questionnaire was the main instrument used in the study. The questionnaire was based on the recommended sanitation and food safety standards from the Sanitation Code of the Philippines, Good Manufacturing Practices (GMP), Sanitary Standards and Operating Procedures (SSOP), Serv Safe, ASEAN Common Competency Standards for Tourism Professionals (ACCSTP), ISO 22000. Draft of the questionnaires was given to the 
statistician comments for clarity and content. Identified vague phrases and words were replaced with appropriate terminologies. See Appendix B for a copy of the questionnaire.

In order to ensure validity of the research instruments, the questionnaires was presented to a group of HRM Instructors, managers and some kitchen staff from the nonparticipating fast-food chain and hotel. Comments and suggestions were gathered and consolidated to make the necessary modification.

\section{Procedure}

Permissions from the different managers and supervisors from fast food chains and deluxe hotels were sought prior to the distribution of the questionnaires. A cover letter duly signed by the researcher explaining the purpose of the survey was prepared. The letter also stated the confidentiality of the results that will be obtained from the respondents. Assistance from various managers, supervisors and OJT students was likewise sought to facilitate the administration and retrieval of the questionnaires. The survey questionnaire was coupled with informal interview to validate responses. The results were collated, summarized and used in the construction of the proposed competency-based modules in Food Sanitation and Safety.

\section{Data Analysis}

Data gathered were compiled, sorted out, organized and tabulated using the following statistical treatment to answer the research questions presented in the study. Percentage was used to show the relationship between two magnitudes, or the relationships of a part to its whole. Frequency distribution was utilized to determine the profile of the business establishments and the participants of the study. Weighted Mean was adapted to the respondents' perception on the food sanitation and safety practices with regards to general and functional competencies. Independent Sample t-test was used to know the significant difference between the ratings of the participating hotels and fast-food chain. ANOVA was used to determine the significant difference in the perception of kitchen staff on the sanitation and safety practices of selected fast-food chains and fine dining restaurant and bars in deluxe hotel.

\section{RESULTS AND DISCUSSION}

\section{Mapped Food Sanitation and Safety Standards}

Presented here is the mapped food sanitation and safety standards lifted from Presidential Degree 856 or Sanitation Code of the Philippines, Good Manufacturing Practices (GMP), Sanitary Standards and Operating Procedures (SSOP), Serv Safe, ASEAN Common Competency Standards for Tourism Professionals (ACCSTP), ISO 22000 were deemed necessary in the operation of a kitchen. The standards were grouped into the following areas: requirements for a food handler and requirements for inclusive of kitchen operations ordering and purchasing, receiving and storage, preparation, cooking and holding, cleaning and disposal of garbage. 
Table 2 indicates that requirements for a food handler in food manufacturing establishments have defined standards than commercial cooks in the kitchens. Food handler in manufacturing companies must follow the standards prescribed by Good Manufacturing Practices (GMP), Standard Sanitary Operating Procedures (SSOP), and ServSafe, unlike commercial cooks, who only have to comply with P.D. 856.

Table 2

Mapped Food Sanitation and Safety Standards (Requirement for a Food Handler, Ordering and Purchasing)

\begin{tabular}{|c|c|c|}
\hline Standards & $\mathbf{f}$ & $\%$ \\
\hline \multicolumn{3}{|l|}{ 1. Requirement for a Food Handler / Kitchen Steward } \\
\hline 1.1. Wear clean working garments & 5 & $71 \%$ \\
\hline 1.2. Wear prescribed caps and hairnets & 5 & $71 \%$ \\
\hline 1.3. Wash hands thoroughly immediately before work, after visiting toilet & 5 & $71 \%$ \\
\hline 1.4. Observe personal hygiene & 6 & $86 \%$ \\
\hline 1.5. Undergo physical and medical examinations annually. & 5 & $71 \%$ \\
\hline $\begin{array}{l}\text { 1.6 Qualified and experienced persons directly supervising the kitchen } \\
\text { activity }\end{array}$ & 3 & $43 \%$ \\
\hline 1.7. Responsibilities are defined, staff trained in duties and GMP & 5 & $71 \%$ \\
\hline 1.8. Undergone food safety training & 6 & $86 \%$ \\
\hline $\begin{array}{l}\text { 1.9. Training programs are documented, reviewed and updated when } \\
\text { necessary. }\end{array}$ & 5 & $71 \%$ \\
\hline $\begin{array}{l}\text { 1.10. Observe reasonable measures to any person shown to have lesions, } \\
\text { wounds, or any illness. }\end{array}$ & 4 & $57 \%$ \\
\hline 1.11. Remove all unsecured jewelry, objects while on duty. & 4 & $57 \%$ \\
\hline 1.12. Use gloves in food handling in an intact, clean and sanitary condition & 3 & $43 \%$ \\
\hline 1.13. Store clothing or other personal belongings in locker rooms & 4 & $57 \%$ \\
\hline $\begin{array}{l}\text { 1.14. Use confined areas purposely for eating, chewing gum, drinking } \\
\text { beverages and using tobacco. }\end{array}$ & 4 & $57 \%$ \\
\hline 1.15. Keep fingernails short and clean with no nail polish & 3 & $43 \%$ \\
\hline \multicolumn{3}{|l|}{ 2. Ordering and Purchasing } \\
\hline $\begin{array}{l}\text { 2.1. Suppliers get products from licensed, reputable purveyors and } \\
\text { manufacturers. }\end{array}$ & 5 & $71 \%$ \\
\hline $\begin{array}{l}\text { 2.2. Meat and fish products shall not be procured from areas affected by } \\
\text { radioactivity, or contaminated environment. }\end{array}$ & 5 & $71 \%$ \\
\hline $\begin{array}{l}\text { 2.3. Milk and fluid products are obtained from approved sources and } \\
\text { sterilized, pasteurized or heated }\end{array}$ & 5 & $71 \%$ \\
\hline
\end{tabular}

For areas in the kitchen like ordering and purchasing, receiving and storage, preparation, cooking and holding, cleaning and disposal of garbage, it was likewise noticeable that the food sanitation and safety standards in food manufacturing plants are also strictly defined compared with a commercial kitchen. 
Table 3.

Mapped Food Sanitation and Safety Standards (Receiving and Storage, Preparation, Cooking and Holding)

\begin{tabular}{|c|c|c|}
\hline Standards & $\mathbf{f}$ & $\%$ \\
\hline \multicolumn{3}{|l|}{ 3. Receiving and Storage } \\
\hline $\begin{array}{l}\text { 3.1. Observe temperature range in storing dry foods, perishable and non- } \\
\text { perishable item. }\end{array}$ & 5 & $71 \%$ \\
\hline $\begin{array}{l}\text { 3.2. Use calibrated thermometer to check the temperature of foods } \\
\text { received. }\end{array}$ & 5 & $71 \%$ \\
\hline $\begin{array}{l}\text { 3.3. Storage areas and compartments are kept clean, free from odors and } \\
\text { in good repair }\end{array}$ & 5 & $71 \%$ \\
\hline $\begin{array}{l}\text { 3.4. Appropriate and sufficient racks and shelves are used for washed } \\
\text { utensils }\end{array}$ & 4 & $57 \%$ \\
\hline $\begin{array}{l}\text { 3.5. Incoming materials are inspected, segregated until checked in } \\
\text { designated quarantine area }\end{array}$ & 5 & $71 \%$ \\
\hline 3.6. Reject, recall unidentified and quarantined; records. & 4 & $57 \%$ \\
\hline 3.7. Protection from heat, lights and moisture is provided & 3 & $43 \%$ \\
\hline 3.8. Receive materials that are properly labeled & 5 & $71 \%$ \\
\hline 3.9. Records allow full traceability of distributed stock & 6 & $86 \%$ \\
\hline 3.10. Documentation and standard operating procedures are observed. & 5 & $71 \%$ \\
\hline $\begin{array}{l}\text { 3.11. Specifications for materials, products and product containers are } \\
\text { used and documented }\end{array}$ & 5 & $71 \%$ \\
\hline 3.12. Containers specifications consistent with contract particulars & 5 & $71 \%$ \\
\hline 3.13. Received deliveries one at a time or during off peak & 1 & $14 \%$ \\
\hline 3.14. Observe "First In First Out" & 3 & $43 \%$ \\
\hline \multicolumn{3}{|l|}{ 4. Preparation, Cooking and Holding } \\
\hline $\begin{array}{l}\text { 4.1. Raw fruits, vegetables and washable raw materials are thoroughly } \\
\text { washed and inspected before they are used. }\end{array}$ & 5 & $71 \%$ \\
\hline 4.2. Utensils and working table are clean, and sanitized after each used. & 5 & $71 \%$ \\
\hline $\begin{array}{l}\text { 4.3. Separate area away from cooked food is used for the preparation of } \\
\text { meat, fish, poultry. }\end{array}$ & 4 & $57 \%$ \\
\hline $\begin{array}{l}\text { 4.4. Frozen foods are thawed properly either refrigeration, boiling, } \\
\text { microwave or submerge in potable water }\end{array}$ & 1 & $14 \%$ \\
\hline 4.5. Cook food properly observing temperature requirement & 5 & $71 \%$ \\
\hline 4.6. Use properly calibrated thermometers when cooking & 5 & $71 \%$ \\
\hline 4.7. Avoid overloading ovens, fryers and cooking equipment & 4 & $57 \%$ \\
\hline 4.8. Use batch cooking when cooking volume dishes & 3 & $43 \%$ \\
\hline 4.9. Shallow stainless steel pans are used for dense foods like stew, chilli & 3 & $43 \%$ \\
\hline 4.10. Observe Four Hour rule in holding food. & 2 & $29 \%$ \\
\hline 4.11.Foods are served fresh from the kitchen at desired temperature & 5 & $71 \%$ \\
\hline
\end{tabular}


Table 4.

Mapped Food Sanitation and Safety Standards in terms of Cleaning and Garbage Disposal

\begin{tabular}{|l|c|c|}
\hline \multicolumn{1}{|c|}{ Standards } & f & $\%$ \\
\hline \multicolumn{1}{|c|}{ 5. Cleaning and Garbage Disposal } & $\mathbf{5}$ & $\mathbf{7 1 \%}$ \\
\hline $\begin{array}{l}\text { 5.1. Dispose of any rejected material in a hygienic manner } \\
\text { 5.2. Use separate storage area away from food storage for cleaning and } \\
\text { chemical supplies }\end{array}$ & $\mathbf{5}$ & $\mathbf{7 1 \%}$ \\
\hline $\begin{array}{l}\text { 5.3. Implement pest control program } \\
\text { 5.4. Toilet rooms, fixtures and locker rooms are clean regularly by non } \\
\text { kitchen personnel }\end{array}$ & $\mathbf{5}$ & $\mathbf{7 1 \%}$ \\
\hline $\begin{array}{l}\text { 5.5. Refuse storage space with scrubbing brushes, detergents, and hot } \\
\text { under pressure water }\end{array}$ & $\mathbf{5 7 \%}$ \\
\hline \begin{tabular}{l} 
5.6. Use holding bins for garbage with tight fighting cover \\
\hline 5.7. There is sufficient drainage to handle waste water
\end{tabular} & $\mathbf{7 1 \%}$ \\
\hline $\begin{array}{l}\text { 5.8. Use personnel protective equipment } \\
\text { 5.9. Observe garbage segregation }\end{array}$ & $\mathbf{5}$ & $\mathbf{7 1 \%}$ \\
\hline 5.10. Use separate disposing unit for oil & $\mathbf{5}$ & $\mathbf{7 1 \%}$ \\
\hline
\end{tabular}

Hazard Analysis and Critical Control points (HACCP), a system of quality control management, places the responsibility in the hands of manufacturers and handlers of food product. It emphasizes on procedures of food control based on the prevention of food safety problems. Within the restaurant industry, while HACCP is not government mandated, it is now program of many restaurants wherein voluntarily implemented as a means of food-safety control. The HACCP program is usually monitored by the Executive Chef or General Manager who is responsible for maintaining the integrity of the restaurant. ISO 22000 on the other hand, is a food safety management system that adopts the standards of HACCP. It is one of the highest certification that is given to a food establishment.

\section{Extent of Practice of Harmonized Standards in Food Sanitation and Safety in Deluxe Hotels and Fast-food chains}

The standards for food handler presented to participating deluxe hotels and fast-food chains are accepted and practiced to a very great extent. ServSafe also confirmed that beginning an entire safe operation recognizes good personal hygiene and good work practices. HACCP also mentioned that even government may not mandate, restaurants voluntarily implementing as a means of food-safety control. Pennsylvania Food Industry Council allude from its website on Food Safety that good personal hygiene practices are vital in making food safe during production.

Code on sanitation also requires food practitioner and establishment to comply with its existing provision particularly in practicing personal hygiene. De Leon and Vivas (2007) mentioned that hygienic practices include personal cleanliness, wearing clean and appropriate 
uniform is a key to the prevention of food borne illness. Participating establishments all practiced washing of hands because respondents perceived it as a vital protection and removing pathogenic microorganisms that may contaminate food and cause food-borne illness.

All participants of the study observed measures to detect any visible lesions, cuts and wound among its food handler. Hand gloves are used to handle food for single use; smoking and eating in designated areas; and undergoing physical examination signify that participants recognized the importance of the mentioned standards. All these procedures are observed to prevent pathogenic microorganisms to transfer into foods that may be carried by the food handlers body or present in this lesions. These are legal requirements stated in the Food Safety (General Food Hygiene) Regulations 1995 that requires managers to have provisions for transmitted diseases, infected wounds, skin infection, sores and the like. The law states that employer has the responsibility to ensure that all working food handler maintains a high degree of personal cleanliness, wear suitable clothes and attire and free from any communicable disease.

\section{Extent of practice of Food Sanitation and Safety for Commercial Kitchen Staff/Steward}

Majority of the harmonized standards for commercial kitchen staff and steward are practiced by the participants to a very great extent. According to ServSafe (2008), purchasing from approved suppliers is one of the most important considerations to start in safe food handling. Brownell (2002) mentioned that ensuring food safety starts from the control in the quality and safety of food and qualified suppliers can control hazards. Proper labeling of food items before storing is also observed. Respondents perceived it as important to know its specification, expiration and use. This method also ensures proper stock rotation. Majority of the respondents also practiced the "First In First Out" policy. Respondents viewed it as one of the important things to consider in storing goods to maintain quality and freshness. The use of separate storage containers and racks for dry and non-dry foods and keeping storage shelves are kept clean and properly labeled are strictly observed. It is stated in the Food Safety Regulations of 1995 that all articles, fittings or equipment that come in contact with food must be kept clean at all times.

For preparation and cooking, the use of standardized recipe is also observed. Standardized recipes are followed by the fast-food chains since food items are pre-prepared in the commissary. It was observed that in general the fast-food chains are the only ones that consistently use standard recipe since raw materials are pre-prepared in the Commissary or central kitchen.

On the other hand, hotels also use standardized recipes but more liberated in the implementation. This can be explained by the fact that Chefs have their own unique techniques in food preparation. Deluxe hotels are more lax in this area and allow their Chefs to adjust the recipe according to their taste or acceptability. 
However, the importance of standard recipes to ensure consistent monitoring and control over the other factors that will make food unsafe cannot be over emphasized. Standardized recipes also assure consistent quality and taste of the products regardless whoever prepares the food. Organizations like ISO 22000 and HACCP require standardized recipes for uniformity of procedures and consistency in monitoring of food safety.

In the preparation of raw materials or ingredients prior to cooking, participants always practices separation of raw foods from cooked food and clean utensils are used in the preparation of foods. These procedures are intended to prevent cross contamination. Leocadio (1998) mentioned in her study that the amount of bacteria is influenced by unhygienic preparation. She suggested that in order to ensure sanitation, utensils must be washed and cleaned before using. Storing does not only apply to foods but also to utensils used in the operation. These may also be the source of microorganism that contaminates food and eventually lead to physical, chemical or biological hazards

Storage areas of frozen goods are defrosted and cleaned regularly. Defrosting allows the equipment to clean its coils, and melt ice crystals that may affect the efficiency in cooling foods. Frost and dirt will impair the operation of the unit. Cleaning refrigerator the racks and trays and use of a fungicide at least once a week, or more often is necessary to maintain a sanitary condition and to prevent transfer of odour.

In serving foods, sanitized tools are used for service and foods are served at desired temperature. The uses of sanitized containers where utensils are held and stored were highly observed by the participants. In the food business, preparation represents an integral stage in the processing of raw materials to produce a quality finished food product. The Pennsylvania Food Industry Council and Serv Safe (2008) stressed the importance of controlling temperatures throughout the stages of processing which are vital in making food safe.

The use of bacterial treatment is also observed. This allows the remaining bacteria to be destroyed during cleaning using the chemical cleaning agents. Cleaning, disposing and holding of garbage properly is a significant concern among the respondents. Waste not properly secured is a hygiene and safety risk. The sight of it offends customers. All garbage should be disposed of as often as is necessary to prevent nuisances. This prevents rodent infestation. Proper storage of garbage is most important because improper storage practices often attract vermin to the establishment.

\section{Differences Between the Ratings of the Participating Hotels and Fast-food Chains}

Table 5 shows the differences between the ratings of the participating hotels and fastfood chains. 
Table 5

Difference between the ratings of the participating hotels and fast food chain. $\mathrm{df}=26 ; \alpha=0.05$

\begin{tabular}{|c|c|c|c|c|c|}
\hline $\begin{array}{c}\text { Food Sanitation and } \\
\text { Safety Practices in } \\
\text { terms of }\end{array}$ & $\mathbf{t}_{\text {computed }}$ & $\mathbf{t}_{\text {table }}$ & $\begin{array}{c}\text { Sig. } \\
\text { Value }\end{array}$ & Decision & Interpretation \\
\hline $\begin{array}{c}\text { Requirement for a } \\
\text { Food Handler }\end{array}$ & 1.099 & 2.056 & 0.282 & Rejected & Not Significant \\
\hline Kitchen Operations & 0.968 & 2.056 & 0.342 & Rejected & Not Significant \\
\hline
\end{tabular}

It can be noted from Table 9 that there is no difference on the practice of the harmonized standards among the participating establishments since the computed $t$ value of (1.099) and (0.968) respectively among food handler and commercial kitchen staff are less than the tabular value of 2.056 with a degree of freedom of 26 at 0.05 level of significance. Therefore, the hypothesis of no significant difference in the sanitation and safety practices in fast-food chains and fine dining restaurants of hotels is rejected. It indicates that the participating establishments have the same practice with regards to the harmonized food sanitation and safety standards.

There is no significant difference on the perception of the sanitation and safety practices since they view it as generic practice in the foodservice establishment. Supervisors cited that sanitation and safety practices are similar since they are dealing with same raw material which is food. However, variations may be observed as affected by the menu, type of operation and volume of production.

Participants of the survey mentioned that among the Deluxe hotels, sanitation and safety programs may differ in approach but the same in rationale which all boils down to preventing food from being hazardous or bringing danger if improperly handled. They also mentioned that any level of the kitchen organization follows the same sanitation and safety program.

Differences on the Perception of the Respondents Regarding the Food Sanitation and Safety Practices When Grouped according to Profile Variables.

Table 6 shows the differences on the perception of the respondents on the food sanitation and safety practices according to their profile such as: position in the kitchen, gender, length of service and educational attainment. 
Table 6

Differences on the Responses on the Sanitation and Safety Practices as Perceived by the Respondents

$\alpha=0.05$

\begin{tabular}{|l|c|c|c|c|c|c|c|c|}
\hline \multicolumn{1}{|c|}{ Profile Variables } & \multicolumn{4}{|c|}{ Food Handler } & \multicolumn{4}{c|}{ Kitchen Operation } \\
\hline & $\mathbf{F}_{\text {computed }}$ & $\mathbf{F}_{\text {table }}$ & $\begin{array}{c}\text { Sig. } \\
\text { Value }\end{array}$ & Decision & $\mathbf{F}_{\text {computed }}$ & $\mathbf{F}_{\text {table }}$ & $\begin{array}{c}\text { Sig. } \\
\text { Value }\end{array}$ & Decision \\
\hline $\begin{array}{l}\text { Position in the } \\
\text { Kitchen }\end{array}$ & 0.564 & 3.01 & 0.644 & Rejected & 1.541 & 3.01 & 0.230 & Rejected \\
\hline Gender & 0.597 & 4.23 & 0.447 & Rejected & 3.090 & 4.23 & 0.091 & Rejected \\
\hline Length of Service & 1.571 & 3.39 & 0.228 & Rejected & 0.995 & 3.39 & 0.384 & Rejected \\
\hline $\begin{array}{l}\text { Educational } \\
\text { Qualification }\end{array}$ & 0.525 & 2.80 & 0.718 & Rejected & 1.177 & 2.80 & 0.347 & Rejected \\
\hline
\end{tabular}

Table 10 shows that computed $F$ values are less than the tabular value at 0.05 level of significance. Therefore, the hypothesis on significant difference in the perception of kitchen staff on the sanitation and safety practices of participating fast-food chains and hotel restaurants is rejected. This means that there is no difference existing between the mentioned variables. This also implies that whatever is the position of the staff, whether male or female, whether how long they are in the business and whether the respondents are college graduate or not, there is no variation in their response.

It can be noted from the respondents that their establishments have provided intensive food sanitation and safety trainings among its employees that may resulted to same responses from the respondents. Besides training, it was noted from the responses of the participants that regular monitoring through audit and inspection was conducted to ensure that food safety procedures set by the management is observed at all times.

The company also ensures that hired personnel can execute the standards their company has implemented. Skills and competencies of the kitchen staff are properly identified in each company. The study of Sampiano (2011) recognizes the importance of certain skills and competencies in performing job in foodservice establishments like setting rules, regulations and ensuring these are being followed.

To summarize, it is important to hire personnel that has the skills and competencies required for each job. Furthermore, continuous training, consistent monitoring and controlling of the operation is the key to ensure a high level of food sanitation and safety practices in the establishment.

\section{Proposed Competency-Based Modules in Food Sanitation and Safety}

It is evident from the results of this research study that there is a big need to educate and train people who wish to build a career in the food and restaurant industries on food 
safety. As per the Commission on Higher Education (CHED) requirement, it requires future hospitality practitioner and students should have an introduction on the significance of safety, sanitation and hygiene principles and sound practices to prevent the outbreak of food-borne illnesses and intoxication. It is in the perspective that the proposed competency-based modules on food sanitation and safety had been developed.

The format of the modules complements CHED and TESDA's competency approach to education and training. Each module consists of specific learning outcomes and nominal duration that explain what tasks and competence should be accomplished and acquired in due time. Assessment criteria and method listed in every module emphasizes the knowledge, skills, and attitudes that must be demonstrated by learners at the conclusion of each learning outcome, and the appropriate methods to be used to gather evidence about a student's competency.

The content listed in each module shows the knowledge skills and attitude a food handler must observe while working in the kitchen. On the other hand, the facilities and learning resources provided in each module specify the conditions and learning resources under which the learning assessment will take place. Teaching methodology is also listed in each module to specify the teaching strategies to be used to convey the content to the learner.

\section{CONCLUSIONS AND RECOMMENDATIONS}

The safety of consumers is the paramount responsibility of any food service establishment. Standards, procedures and guidelines are developed to prevent the outbreak of food-borne illnesses and intoxication. However, these standards, procedures and guidelines as food sanitation and safety will be meaningless if they are not study implemented through education, information, dissemination, and training among the personnel. Food safety is everybody's concern. It is in this context that the researcher tried in her own little way to help by proposing these competency-based modules.

It hereby recommended that there is a need to update the Sanitation Code of the Philippines to be abreast with international standards. This would be done through proper legislation in the congress. Educating and training the young on proper sanitation, hygiene and safety should start early at home and in school. Food service establishments should be HACCP, ISO 22000 certified to upgrade their food safety programs. More researches on food safety should be conducted by higher education institutions to help prevent outbreaks of food-borne illnesses. This competency-based module should be pilot tested among higher education institutions to test its effectiveness as a teaching tool. Increase unit requirement and scope of Food Safety subject among Food Science or related programs which includes lecture (3 units) and laboratory (2units). Design a food safety short term or degree program which will have a thorough study on the various areas of food production, food service operation that focuses on food sanitation and safety. Escalate the scope of Food Sanitation and Safety course for HRM, Culinary and food service related courses. Further study on the basic safety in the kitchen which 
included first aid, basic fire prevention and occupational health and safety maybe done in realization to this study.

\section{References}

Brownell, Judi and Reynolds, Dennis (2002). Strengthening the F \& B Purchaser-Supplier Partnership. Cornell Hotel and Restaurant Administration Quarterly.

Commission on Higher Education(CHED) Memorandum Order No. 30 series 2006.

De Leon, Sonia Y and Vivas Lara, (2007), Application of 5-in 1 Food Safety Systems in the workplace. Foundation for advancement of Food Science and Technology, Inc. Philippines.

Food Safety (General Food Hygiene) Regulations 1995, available online: http://www.opsi.gov.uk/si/si1995/Uksi_19951763_en_4.htm

Leocadio, Corazon G. (1998), Essentials of Meal Management. Unpublished Master's Thesis, University of the Philippines, Diliman Quezon City.

Republic Act No. 7722, Higher Education Act of 1994.

Sampiano, Filipina S. Educational and Skills Requirements of Food service Personnel in Some Selected Food Service Establishments in Metro Manila. Unpublished Masteral Thesis. Eulogio "Amang" Rodriguez, Institutte of Science and Technology, Manila.2001

Walker, John R. (2004). Introduction to Hospitality Management. Upper Saddle River, New Jersey: Pearson Education, Inc. 